\title{
Article
}

Subscriber access provided by King Abdullah University of Science and Technology Library

\section{Imine Metathesis Catalyzed by a Silica-supported Hafnium Imido Complex}

Maha A. Aljuhani, Samir Barman, Edy Abou-Hamad, Andrei A. Gurinov, Samy Ould-Chikh, Erjia Guan, Abdesslem Jedidi, Luigi Cavallo, Bruce C. Gates, Jeremie D. A. Pelletier, and Jean-Marie Basset

ACS Catal., Just Accepted Manuscript • DOI: 10.1021/acscatal.8b01395 • Publication Date (Web): 04 Sep 2018

Downloaded from http://pubs.acs.org on September 9, 2018

\section{Just Accepted}

\begin{abstract}
"Just Accepted" manuscripts have been peer-reviewed and accepted for publication. They are posted online prior to technical editing, formatting for publication and author proofing. The American Chemical Society provides "Just Accepted" as a service to the research community to expedite the dissemination of scientific material as soon as possible after acceptance. "Just Accepted" manuscripts appear in full in PDF format accompanied by an HTML abstract. "Just Accepted" manuscripts have been fully peer reviewed, but should not be considered the official version of record. They are citable by the Digital Object Identifier (DOI®). "Just Accepted" is an optional service offered to authors. Therefore, the "Just Accepted" Web site may not include all articles that will be published in the journal. After a manuscript is technically edited and formatted, it will be removed from the "Just Accepted" Web site and published as an ASAP article. Note that technical editing may introduce minor changes to the manuscript text and/or graphics which could affect content, and all legal disclaimers and ethical guidelines that apply to the journal pertain. ACS cannot be held responsible for errors or consequences arising from the use of information contained in these "Just Accepted" manuscripts.
\end{abstract}




\title{
Imine Metathesis Catalyzed By A Silica-Supported Hafnium Imido Complex
}

\author{
Maha A. Aljuhani, ${ }^{\text {a§ }}$ Samir Barman, ${ }^{\text {a }}$ Edy Abou-Hamad, ${ }^{\mathrm{a}+}$ Andrei Gurinov, ${ }^{\mathrm{a}+}$ Samy Ould-Chikh,,${ }^{\text {as }}$ \\ Erjia Guan, ${ }^{b}$ Abdesslem Jedidi, ${ }^{c}$ Luigi Cavallo, ${ }^{a s^{*}}$ Bruce C. Gates, ${ }^{\mathrm{d}^{*}}$ Jérémie D. A. Pelletier $^{\mathrm{a} \S^{*}}$ and Jean- \\ Marie Basset ${ }^{\text {as* }}$

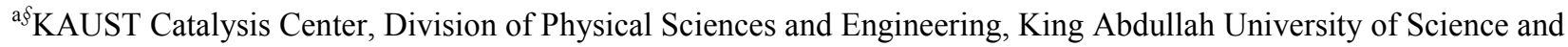 \\ Technology (KAUST), Thuwal 23955-6900, Kingdom of Saudi Arabia.
}

\author{
${ }^{a+}$ King Abdullah University of Science and Technology (KAUST), Core Labs, Thuwal, 23955-6900, Kingdom of Saudi \\ Arabia \\ ${ }^{b}$ Department of Materials Science and Engineering, University of California, Davis, Davis, CA 95616, United States. \\ ${ }^{\mathrm{c}}$ Department of Chemistry, Faculty of Science, King Abdulaziz University, Jeddah 21589, Kingdom of Saudi Arabia. \\ ${ }^{\mathrm{d}}$ Department of Chemical Engineering, University of California, Davis, Davis, CA 95616, United States.
}

\section{Supporting Information Placeholder}

\begin{abstract}
Well-defined single-site silica-supported hafniaaziridine complex $\left[(\equiv \mathrm{Si}-\mathrm{O}-) \mathrm{Hf}\left(\eta^{2} \pi-\mathrm{MeNCH}_{2}\right)\left(\eta^{1}-\mathrm{NMe}_{2}\right)\left(\eta^{1}-\right.\right.$ $\left.\mathrm{HNMe}_{2}\right)$ ] was prepared using surface organometallic chemistry. Upon thermal treatment under high vacuum, the grafted species was converted into an unprecedented hafnium imido, bis-amido, complex $\left[(=\mathrm{Si}-\mathrm{O}-) \mathrm{Hf}(=\mathrm{NMe})\left(\eta^{1}-\mathrm{NMe}_{2}\right)\right]$. The surface complexes were characterized by elemental analysis and the following spectroscopic techniques: infrared, solid-state single and multiple quantum NMR, advanced DNP-SENS, and extended X-ray absorption fine structure. $\left[(\equiv \mathrm{Si}-\mathrm{O}-) \mathrm{Hf}(=\mathrm{NMe})\left(\eta^{1}-\mathrm{NMe}_{2}\right)\right]$ catalyzed imine metathesis under mild conditions, and characterization of the reactivity showed that the imido exchange with $\mathrm{N}-(4-$ phenylbenzylidene)benzylamine yielded $\quad[(\equiv$ Si-O- $) \mathrm{Hf}$ $\left.\left(=\mathrm{NCH}_{2} \mathrm{Ar}\right)\left(\eta^{1}-\mathrm{NMe}_{2}\right)\right]$, demonstrating a kind of $2+2$ mechanism involving the imine and the imido, proposed reaction mechanism is also supported by DFT calculations.
\end{abstract}

KEYWORDS: heterogeneous catalysis, imine metathesis, SOMF, metalaziridine, and imido fragment.

\section{INTRODUCTION}

Understanding of a wide range of catalysts on surfaces has benefited from the fundamental approach referred to as "surface organometallic chemistry" (SOMC), whereby molecular organometallic compounds react with support surface functional groups to precisely synthesize surface species that are characterized in depth by spectroscopic methods. ${ }^{1-2}$ This approach has developed into "Catalysis by Design," with surface organometallic fragments (SOMFs) selected to be intermediates in presumed catalytic cycles. Most of the well-documented SOMFs incorporate hydrocarbon ligands ( $M-R, M=C, M \equiv C R$, etc.), but, recently, a similar level of understanding has emerged for metal-amide complexes grafted on highly dehydroxylated silica surfaces as shown in (Scheme 1). A variety of examples of catalysis were observed with these complexes, including the hydroaminoalkylation of alkenes and the metathesis of imines, depending on the supported metal/nitrogen-containing-ligand combination, $\mathrm{M}-\eta^{2} \mathrm{NRCHR}$ or $\mathrm{M}=\mathrm{NR}$, respectively. ${ }^{3-4}$ The reported work on such catalysts is largely focused on imido or amido complexes (e.g., of molybdenum), ${ }^{5-6}$ and the nitrogen-containing ligands were generally found to be mere spectators. But recent evidence of $\mathrm{Zr}=\mathrm{N}$ surface fragments $\mathrm{s}^{3}$ performing imine metathesis catalysis triggered our interest in determining whether this reactivity is specific to zirconium or can be extended to other metal such as hafnium.

The imine metathesis reaction has been known since 1922, beginning with the report of Ingold and Piggott. ${ }^{7}$ Research reported 50 years later showed that an acid catalyst is required for this reaction, and the authors postulated the presence of an ionic intermediate. $^{8}$ More recently Meyer et al. ${ }^{9}$ synthesized a $\mathrm{Zr}$ containing 2,4-diazametallacyclobutane. A recent report by $\mathrm{Di}$ Stefano et al. ${ }^{10}$ showed that even minute amounts of primary amines can catalyze imine metathesis. Typically, the catalysts were applied at about $100^{\circ} \mathrm{C}$ in organic solvents.

Early transition metal catalysts supported on silica have been reported for imine metathesis catalysis $\left(\mathrm{Zr}^{3,}{ }^{31} \mathrm{Mo}^{12}\right)$ with some unprecended catalytic surface intermediates being isolated.

Interest in olefin metathesis has been intense for decades, triggering continuing efforts to discover new and improved catalysts. Attention has been focused on reactions of molecules containing heteroatoms and on catalysts incorporating various transition metals. Particular interest has focused on molecules that incorporate a heteroatom in the double bond and not only an $\mathrm{sp}^{2} \mathrm{C}$ olefinic carbon. 
The work reported herein extends the classes of $\mathrm{M}-\mathrm{N}$ and $\mathrm{M}=\mathrm{N}$ SOMFs as shown in (Scheme 1), by reported examples with hafnium using preparation strategy is akin to that employed for zirconium. $^{3}$

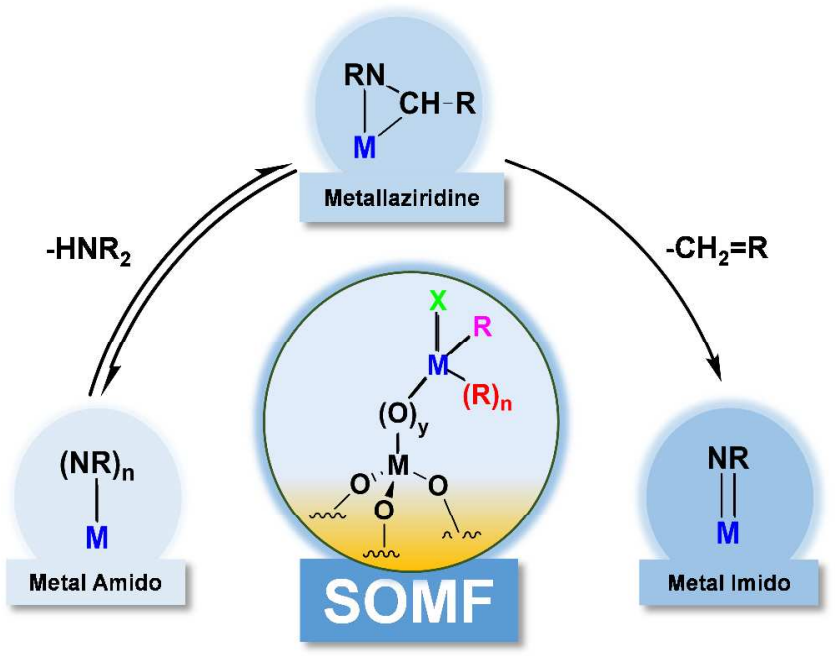

Scheme 1. Schematic representation illustrating the conversion of the surface organometallic fragments (SOMF).

\section{RESULTS AND DISCUSSION}

Highly dehydroxylated silica (pretreated thermally under high vacuum at $700^{\circ} \mathrm{C}, \mathrm{SiO}_{2-700}$, and incorporating $\left.0.3 \mathrm{mmol} \mathrm{OH} / \mathrm{g}\right)^{13}$ was treated with an equivalent amount $(0.33 \mathrm{mmol})$ of the precursor $\left[\mathrm{Hf}\left(\mathrm{NMe}_{2}\right)_{4}\right]$ in pentane to afford silica-supported material $\mathbf{1}$ (see the Supporting Information (SI) for details). The volatile components of 1 were removed by evacuation under high vacuum to yield a white powder. Following thermal treatment of $\mathbf{1}$ at $200^{\circ} \mathrm{C}$ under dynamic vacuum $\left(10^{-5}\right.$ mbar $)$ for $4 \mathrm{~h}$, a new lightpink material $\mathbf{2}$ was generated. 1 and $\mathbf{2}$ were characterized by elemental analysis, infrared (IR) spectroscopy, and solid-state (SS) NMR spectroscopy. Further, 1 was characterized by dynamic nuclear polarization surface enhanced solid state (DNP SENS) and extended X-ray absorption fine structure (EXAFS) spectroscopy.

The IR spectra show that the isolated surface silanols on $\mathrm{SiO}_{2}$ 700 were nearly all consumed as the precursor $\left[\mathrm{Hf}\left(\mathrm{NMe}_{2}\right)_{4}\right]$ was grafted, as evidenced by the disappearance of the $3747 \mathrm{~cm}^{-1}$ band in the spectrum of 1 (Figure 1). Concomitantly, strong new bands appeared in the regions $2800-3000 \mathrm{~cm}^{-1}$ (assigned to $v_{\mathrm{C}-\mathrm{H}}$ bands) and $1400-1500 \mathrm{~cm}^{-1}$ (assigned to the $\delta_{\mathrm{C}-\mathrm{H}}$ bands). The elemental analysis (Table S1, SI) of $\mathbf{1}$ determined $\mathrm{N} / \mathrm{Hf}$ and $\mathrm{C} / \mathrm{Hf}$ ratios of 3.8 and 7.1 , respectively. These values are higher than those expected for a monopodal surface species (the respective theoretical values are 3 and 6). The simplest explanation of the difference is that the dimethylamine evolved during the grafting reaction was partially retained on the silica surface, either by physisorption or by coordination to the metal center. ${ }^{14} \mathrm{~A}$ weak signal observed at $3294 \mathrm{~cm}^{-1}\left(v_{\mathrm{N}-\mathrm{H}}\right.$ band) corroborates this inference. These IR results are consistent with the grafting of the amido hafnium complex to the silica via a protonolysis reaction of the amido ligand by surface silanols (with the formation of anchored $\equiv \mathrm{Si}-\mathrm{O}-\mathrm{Hf}$ moieties). The elemental analysis of 2 (Table S1, SI) indicates $\mathrm{N} / \mathrm{Hf}$ and $\mathrm{C} / \mathrm{Hf}$ ratios of 2.5 and 4.6, respectively (theory: 2 and $4)$. The carbon and nitrogen contents declined after heat treatment

IR spectra of 2 (Figure 1) demonstrate a marked decrease in the intensity of the $v_{(\mathrm{C}-\mathrm{H})}$ bands along with the appearance of a new signal at $1595 \mathrm{~cm}^{-1}$. These results suggest the presence of new functional groups (tentatively assigned as a symmetric $v_{(\mathrm{M}-\mathrm{N}-\mathrm{C})}$ band originating from the metal imido fragments $)^{12}$ concomitant with a partial loss of $-\mathrm{C}-\mathrm{H}$ groups.

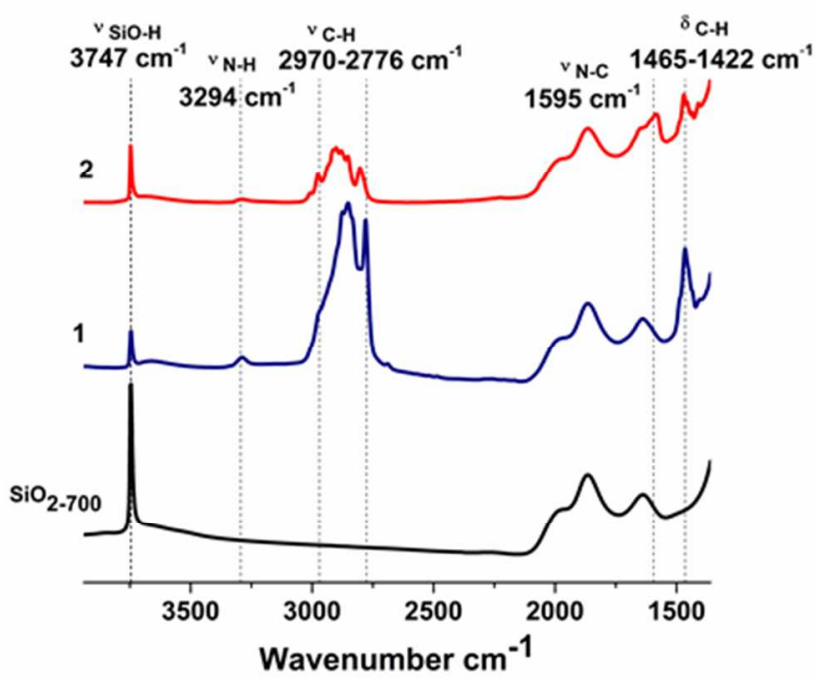

Figure 1. IR spectra of the support, $\mathrm{SiO}_{2-700}$, and the anchored complexes, $\quad\left[(\equiv \mathrm{Si}-\mathrm{O}-) \mathrm{Hf}\left(\eta^{2} \pi-\mathrm{MeNCH}_{2}\right)\left(\eta^{1}-\mathrm{NMe}_{2}\right)\left(\eta^{1}-\mathrm{HNMe}_{2}\right)\right]$ (1) and $\left[(\equiv \mathrm{Si}-\mathrm{O}-) \mathrm{Hf}(=\mathrm{NMe})\left(\eta^{1}-\mathrm{NMe}_{2}\right)\right]$ (2).

Further insights into the coordination spheres of the supported hafnium complexes $\mathbf{1}$ and $\mathbf{2}$ were provided by advanced SS NMR spectroscopy and state-of-the-art DNP-SENS, and EXAFS spectroscopies. The ${ }^{1} \mathrm{H}$ NMR spectrum of $\mathbf{1}$ exhibits overlapping signals at 2.2 and $2.7 \mathrm{ppm}$, as expected from the various alkyl groups bonded to the nitrogen ligands (Figure S1, SI). The ${ }^{13} \mathrm{C} \mathrm{CP}$ MAS spectrum of 1 displays one intense signal at $37 \mathrm{ppm}$ and a shoulder at $46 \mathrm{ppm}$, explained by the nonequivalent methyl groups in $-\mathrm{N}-\left(\mathrm{CH}_{3}\right)_{2}$. A low-field weak resonance at $81 \mathrm{ppm}$ is also correlated with the proton resonance at $2.7 \mathrm{ppm}$ in the HETCOR spectra. This result is consistent with a methylene $\left(\mathrm{CH}_{2}\right)$ group in a 3-membered metallacycle. ${ }^{15}$ Two-dimensional proton double- (DQ) and triple-quantum (TQ) correlation experiments were performed with 1. A strong autocorrelation peak was observed for the signal at $2.2 \mathrm{ppm}$ in both the DQ and TQ spectra (appearing at 4.4 and $6.6 \mathrm{ppm}$ in the $\omega 1$ dimensions, respectively), indicative of methyl protons (Figure 2). However, the proton resonance at $2.7 \mathrm{ppm}$ shows an autocorrelation only in the DQ spectrum and confirms the presence of a methylenic unit $\left(-\mathrm{CH}_{2}-\right)$ in the surface species.

EXAFS spectra of 1 were recorded at the $\mathrm{Hf}_{\mathrm{L}}$ III edge, with the measurements made at liquid nitrogen temperature in a cell described elsewhere (details of the experiments and the data are shown in the SI). ${ }^{16}$ Various plausible models of the supported species were investigated in the data fitting, which is summarized in the SI. The number of statistically justified EXAFS fitting parameters was calculated on the basis of the Nyquist criterion to be 16 , corresponding to at most four shells. Consequently, a combination of $\mathrm{Hf}-\mathrm{N}$, $\mathrm{Hf}-\mathrm{C}$, and $\mathrm{Hf}-\mathrm{O}$ scattering paths was used to build models. The data in the SI include the best-fit parameters for each of several models that represent the data well and a discussion of how the recommended model was selected. We emphasize that, although the EXAFS data alone are not sufficient to determine the structure of $\mathbf{1}$, the recommended model (Table 1) is 
consistent with all the characterization data determined in this work and represented by the sketch shown in (Figure 2c).

The EXAFS data indicate one Hf-O shell with a coordination number of approximately 1.2 at a distance of $1.83 \AA$, which is much shorter than the bonding distances in the bulk compound $\mathrm{HfO}_{2}$ (which range from 2.03 to $2.13 \AA$ ), as determined by X-ray diffraction crystallography (XRD)). ${ }^{16,17}$ A comparison of these distances indicates that hafnium is strongly bonded to the support. The result that this distance is less that the $\mathrm{Hf}-\mathrm{O}$ distance characterizing $\mathrm{HfO}_{2}$ is not surprising; there are examples of hafnium complexes with $\mathrm{Hf}-\mathrm{O}$ distances determined by EXAFS spectroscopy that are similar to the value determined in our work and markedly less that the value characterizing bulk $\mathrm{HfO}_{2}{ }^{17}$ The coordination of the $\eta^{1}-\mathrm{HNMe}_{2}$ ligand is indicated by a $\mathrm{Hf}-\mathrm{N}$ shell with a coordination number of 1.3 at a distance of $2.24 \AA$. The recommended model based on our EXAFS data is consistent with the 3 -membered metallacycle $\left(\eta^{2} \pi-\mathrm{MeNCH}_{2}\right)$, as evidenced by (i) the $\mathrm{Hf}-\mathrm{C}$ shell with a coordination number of 1.3 at a distance of $2.11 \AA$ and (ii) an $\mathrm{Hf}-\mathrm{N}$ shell at a distance of $2.04 \AA$. The latter Hf-N shell in the EXAFS fit has a coordination number of 2.0, because it accounts for both the $\mathrm{N}$ atom in the ring and the $\eta^{1}$ $\mathrm{NMe}_{2}$ ligand; in the combined shell determined in the EXAFS fitting, these are represented with the same Hf-N distance, because the EXAFS data are not sufficient to distinguish these two shells. The lengths found for the $\mathrm{Hf}-\mathrm{N}$ and $\mathrm{Hf}-\mathrm{C}$ bonds are close to those observed by XRD for molecular complexes such as [N[1,1-dimethyl-2-(ethylimino- $\kappa \mathrm{N})$ propyl]-2,6-bis(1-

methylethyl)benzenaminato- $\kappa \mathrm{N}]$ tri $\left(\right.$ methyl-D $\left.\left._{3}\right)\right)$ hafnium $^{18}(2.24 \AA$ for $\mathrm{Hf}-\mathrm{C}$ and $2.08 \AA, 2.30 \AA$ corresponding, respectively, to covalent and coordinate $\mathrm{Hf}-\mathrm{N}$ bonds), $\left[\mathrm{HfC}_{30} \mathrm{H}_{58} \mathrm{~N}_{3} \mathrm{Cl}_{3} \mathrm{Si}_{4}\right]^{19}$ (2.52-2.18 $\AA$ for $\mathrm{Hf}-\mathrm{N}$ and $2.21 \AA$ for $\mathrm{Hf}-\mathrm{C})$, and [(TC$\left.3,3) \mathrm{HfN}(\mathrm{Ar}) \mathrm{C}\left(\mathrm{CH}_{2} \mathrm{Ph}\right)_{2}\right]^{20}(2.14-2.02 \AA$ for $\mathrm{Hf}-\mathrm{N}$ and $2.35-2.26$ $\AA$ for $\mathrm{Hf}-\mathrm{C})$. Note that the calculated $\mathrm{Hf}-\mathrm{O}$ and $\mathrm{Hf}-\mathrm{C}$ distances are both shorter than the reported distances in pure molecular complexes. We tentatively attribute this trend as evidence of the bonding of the $\left[\mathrm{Hf}\left(\mathrm{NMe}_{2}\right)_{4}\right]$ complex to the silica surface.

On the basis of these SS NMR, IR, and EXAFS data, we propose that the surface complex in $\mathbf{1}$ is $\left[(\equiv \mathrm{Si}-\mathrm{O}-) \mathrm{Hf}\left(\eta^{2} \pi-\right.\right.$ $\left.\left.\mathrm{MeNCH}_{2}\right)\left(\eta^{1}-\mathrm{NMe}_{2}\right)\left(\eta^{1}-\mathrm{HNMe}_{2}\right)\right]$ (Figure 2c).

Table 1. EXAFS structure parameters ${ }^{a}$ representing 1.

\begin{tabular}{|c|c|c|c|c|}
\hline Shell & $N$ & $\begin{array}{c}R \\
(\AA)\end{array}$ & $\begin{array}{c}10^{3} \times \Delta \sigma^{2} \\
(\AA)\end{array}$ & $\Delta E_{0}(\mathrm{eV})$ \\
\hline $\mathrm{Hf}-(\underline{\mathbf{O}}-\mathrm{Si} \equiv)$ & $2^{1 .}$ & 1.83 & 2.1 & -8.0 \\
\hline $\mathrm{Hf}-\underline{\mathbf{N}} \mathrm{HMe}_{2}$ & $3^{1 .}$ & 2.24 & 0.2 & -8.0 \\
\hline $\begin{array}{c}\mathrm{Hf}- \\
\mathrm{MeN}^{-}-\mathrm{H}_{2}\end{array}$ & $3^{1 .}$ & 2.11 & 0.2 & -1.0 \\
\hline $\begin{array}{c}\{\mathrm{Hf}- \\
\mathrm{MeNCH}_{2} \\
\text { and } \mathrm{Hf}- \\
\left.\underline{\mathbf{N M e}}_{2}\right\}\end{array}$ & $\begin{array}{l}2 . \\
0\end{array}$ & 2.04 & 0.3 & 2.5 \\
\hline
\end{tabular}

${ }^{a}$ Notation: $N$, coordination number; $R$, distance between $a b$ sorber and backscatterer atoms; $\Delta \boldsymbol{\sigma}^{2}$, disorder term; $\Delta \boldsymbol{E}_{\mathbf{0}}$, inner potential correction. Estimated error bounds: $N, \pm \mathbf{2 0} \% ; R$, $\pm 0.02 \AA ; \Delta \boldsymbol{\sigma}^{\mathbf{2}}, \pm \mathbf{2 0} \% ; \Delta \boldsymbol{E}_{\mathbf{0}}, \pm \mathbf{2 0} \%$. The backscatterers at distances greater than $2.7 \AA$ from the absorber $\mathrm{Hf}$ atom are not fitted in this model. Model II is the recommended best-fit model (more details are presented in the SI).
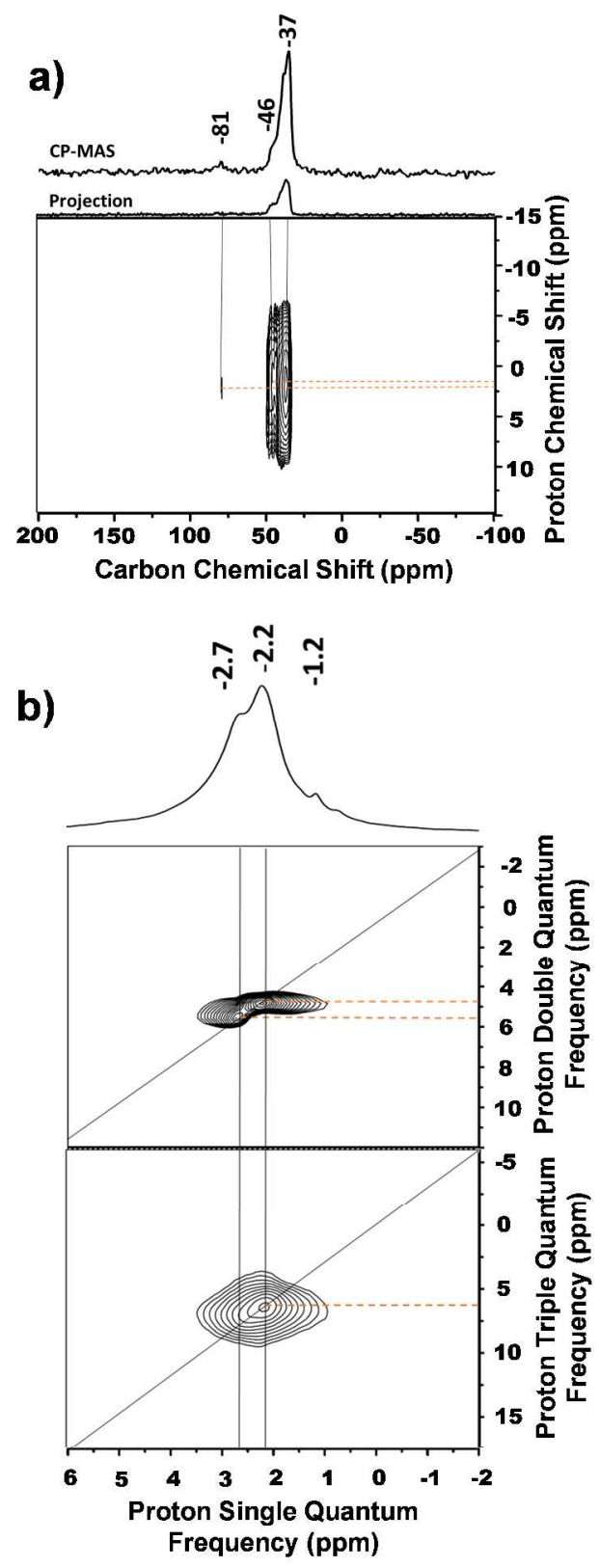

c)

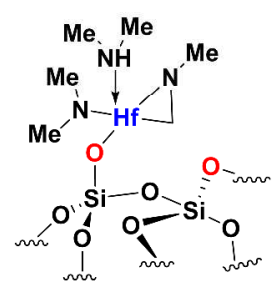

(1)

Figure 2. a) $1 \mathrm{D}{ }^{13} \mathrm{C} \mathrm{CP}$ MAS (top) and $2 \mathrm{D}{ }^{1} \mathrm{H}-{ }^{13} \mathrm{C}$ HETCOR (bottom) NMR spectra of $\left[(\equiv \mathrm{Si}-\mathrm{O}-) \mathrm{Hf}\left(\eta^{2} \pi-\mathrm{MeNCH}_{2}\right)\left(\eta^{1}-\right.\right.$ $\left.\left.\mathrm{NMe}_{2}\right)\left(\eta^{1}-\mathrm{HNMe}_{2}\right)\right](\mathbf{1})$; b) $1 \mathrm{D}{ }^{1} \mathrm{H}$ NMR spectrum (top) and ${ }^{1} \mathrm{H}-$ ${ }^{1} \mathrm{H}$ DQ and ${ }^{1} \mathrm{H}-{ }^{1} \mathrm{H}$ TQ spectra (bottom) of $\mathbf{1}$; c) proposed structure of surface hafnium complex in $\mathbf{1}$.

In contrast to the 1D SS NMR spectra of 1 , those characterizing 2 include mainly a broad band at $2.2 \mathrm{ppm}$, in the ${ }^{1} \mathrm{H}$ NMR spectrum (the weak signal at $1.2 \mathrm{ppm}$ is attributed to some minor impurities, possibly dimethyl amine), and two resonances, at 37 
and $48 \mathrm{ppm}$, in the ${ }^{13} \mathrm{C}$ CP MAS NMR spectrum. Remarkably, no clear signal in the spectra was observed in the region that corresponds to the $\left(-\mathrm{CH}_{2}-\right)$ group of a 3-membered metallacycle (Figure 3). Furthermore, we infer on the basis of multiple quantum experiments that the ${ }^{1} \mathrm{H}$ peaks appearing at $2.2 \mathrm{ppm}$ originates exclusively from the $-\mathrm{CH}_{3}$ groups.
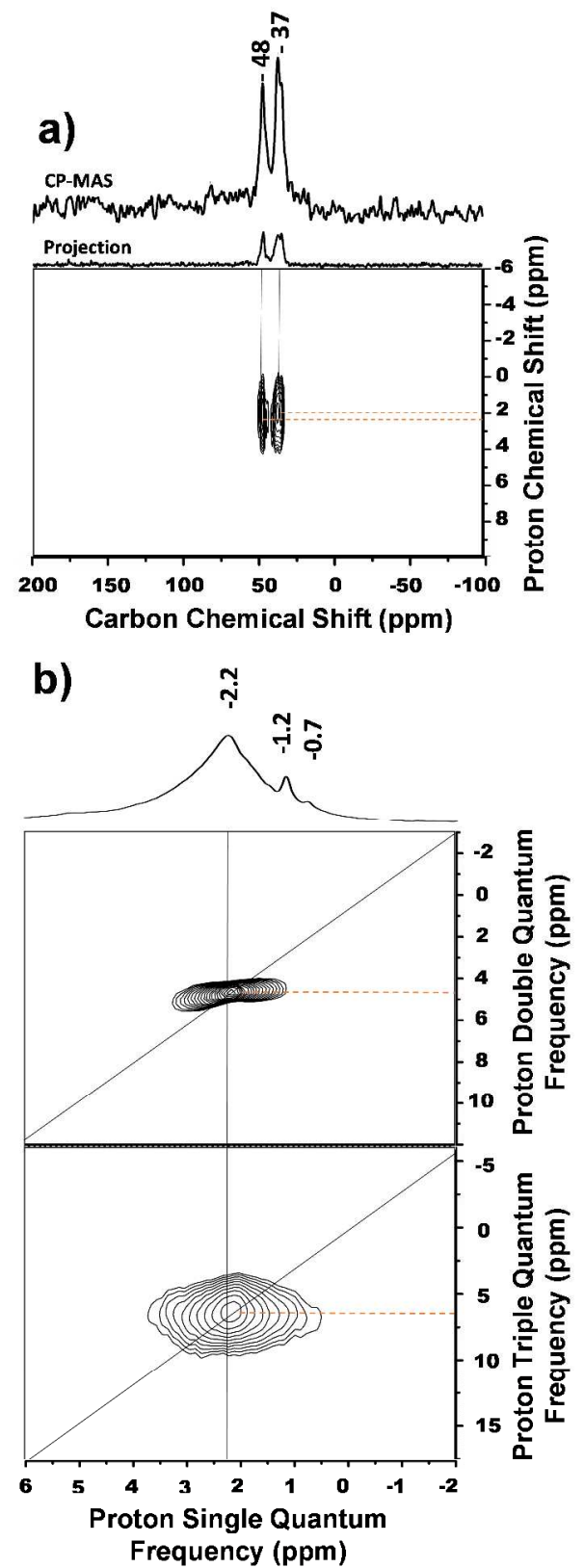

c)

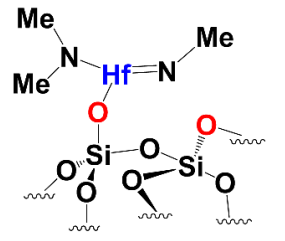

(2)

Figure 3. a) $1 \mathrm{D}{ }^{13} \mathrm{C} \mathrm{CP}$ MAS (top) and $2 \mathrm{D}{ }^{1} \mathrm{H}-{ }^{13} \mathrm{C}$ HETCOR (bottom) NMR spectra of $\left.\left[(\equiv \mathrm{Si}-\mathrm{O}-) \mathrm{Hf}(=\mathrm{NMe})\left(\eta^{1}-\mathrm{NMe}_{2}\right)\right](2) ; \mathrm{b}\right)$ $1 \mathrm{D}{ }^{1} \mathrm{H}$ NMR spectrum (top) and ${ }^{1} \mathrm{H}-{ }^{1} \mathrm{H}$ DQ and ${ }^{1} \mathrm{H}-{ }^{1} \mathrm{H}$ TQ spectra (bottom) of 2; c) proposed structure of surface hafnium complex in 2.

${ }^{15} \mathrm{~N}$ SS NMR spectroscopy experiments were carried out with $\mathbf{1}$ and 2 using the DNP-SENS technique (Figure 4). The spectrum obtained for 1 exhibits two resonances, centered at 7 and $32 \mathrm{ppm}$. On the basis of its relative abundance, we tentatively assign the intense signal shifted downfield at $32 \mathrm{ppm}$ to the ${ }^{15} \mathrm{~N}$ resonances corresponding to the tricoordinated nitrogen sites of the $\left(\eta^{2} \pi-\mathrm{NMeCH}_{2}\right)$ and $\left(-\mathrm{NMe}_{2}\right)$ functionalities. The weak upfieldshifted signal at $7 \mathrm{ppm}$ is compatible with an $\mathrm{NH}\left(\mathrm{CH}_{3}\right)_{2}$ moiety, even after heat treatment - $\mathrm{HNMe}_{2}$ remains on the surface. The comparable spectrum of $\mathbf{2}$ includes an additional signal at 113 ppm along with a signal at $34 \mathrm{ppm}$ that appears to be much less intense than its counterpart at $32 \mathrm{ppm}$ in $\mathbf{1}$. The $113 \mathrm{ppm}$ peak is suggested to originate from the hafnium imido moieties, consistent with the $1595 \mathrm{~cm}^{-1}$ peak in the IR spectrum, vide supra.

These results are in agreement with the conversion of the hafnium metallacycle (M-NR-CH) surface fragment in $\mathbf{1}$ into a metal imido $(\mathrm{M}=\mathrm{N}$ in 2$)$. In view of all the foregoing results, we propose $\left[(\equiv \mathrm{Si}-\mathrm{O}-) \mathrm{Hf}(=\mathrm{NMe})\left(\eta^{1}-\mathrm{NMe}_{2}\right)\right]$ as the structure of $\mathbf{2}$ (Figure $\left.3 \mathrm{c}\right)$. We assume that the coordinated sigma bonded amine $\eta^{1}-\mathrm{HNMe}_{2}$ in $\left[(\equiv \mathrm{Si}-\mathrm{O}-) \mathrm{Hf}\left(\eta^{2} \pi-\mathrm{MeNCH}_{2}\right)\left(\eta^{1}-\mathrm{NMe}_{2}\right)\left(\eta^{1}-\mathrm{HNMe}_{2}\right)\right] \mathbf{1}$ reacts with the coordinated $\mathrm{CH}_{2}$ of the metallacycle to give [( $\equiv \mathrm{Si}-\mathrm{O}-$ ) $\mathrm{Hf}(=\mathrm{NMe})(\eta 1-\mathrm{NMe} 2)] \mathbf{2}$ with formation of $\mathrm{Me}_{3} \mathrm{~N}$ (observed by $\mathrm{GC})$.
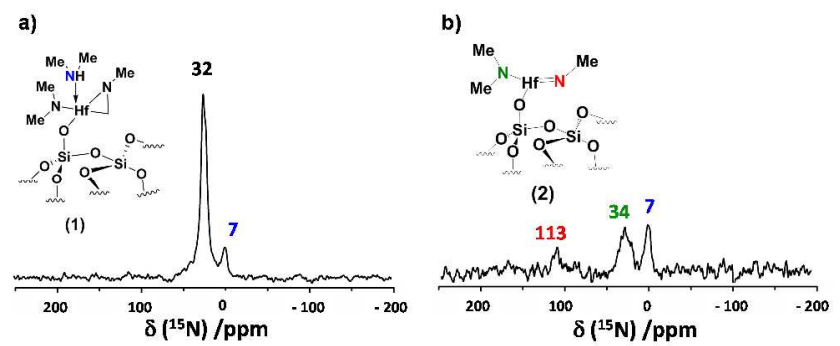

Figure 4. ${ }^{15} \mathrm{~N}$ MAS DNP SENS spectra of a) $\left[(\equiv \mathrm{Si}-\mathrm{O}-) \mathrm{Hf}\left(\eta^{2} \pi-\right.\right.$ $\left.\left.\mathrm{MeNCH}_{2}\right)\left(\eta^{1}-\mathrm{NMe}_{2}\right)\left(\eta^{1}-\mathrm{HNMe}_{2}\right)\right]$ ) $\left.\mathrm{Hf}(=\mathrm{NMe})\left(\eta^{1}-\mathrm{NMe}_{2}\right)\right]$ (2).

(1) and b) $[(\equiv \mathrm{Si}-\mathrm{O}-$

The catalytic performance of $\mathbf{2}$ was evaluated for imine metathesis under conditions similar to those reported: ${ }^{3}$ catalyst $(0.0031$ $\mathrm{mmol}, 4 \mathrm{~mol} \%$ with respect to the imine substrate employed), in toluene (typically $400 \mu \mathrm{L}$ ), at $80^{\circ} \mathrm{C}$ (see Table 1 and SI for details). Three imine substrates were tested: N-(4phenylbenzylidene)benzylamine (a), N-(4-fluorobenzylidene)-4fluoroaniline (b), and N-benzylidene-tert-butylamine (c), (Figure $5)$.

1)

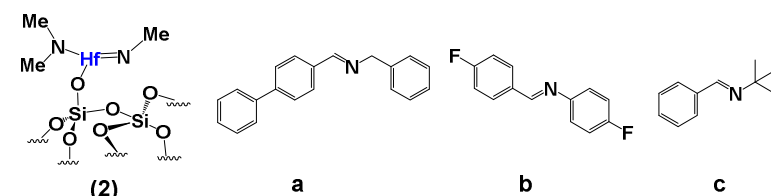

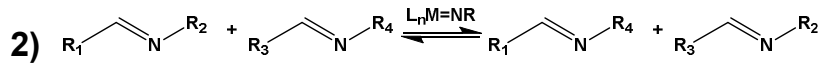




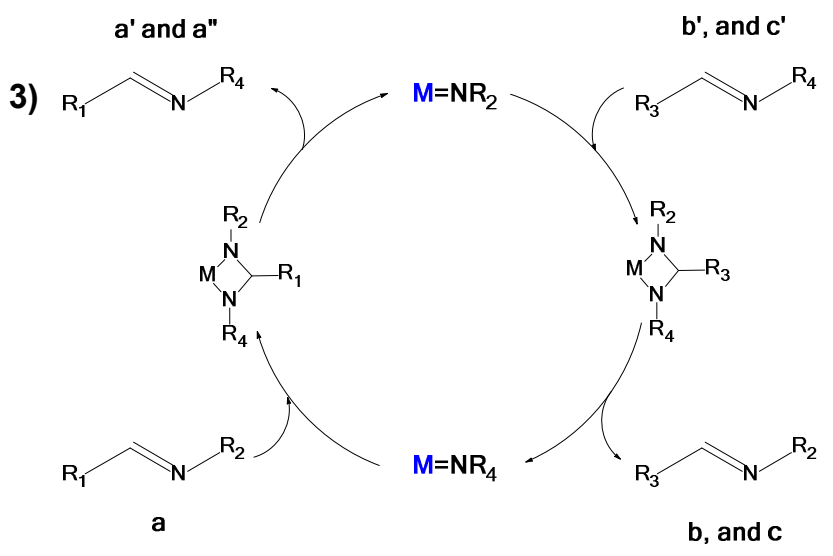

Figure 5. 1) Catalyst 2 and imine substrates, 2) imine metathesis catalysis, and 3) imine metathesis mechanism.

Table 2. Results of catalytic imine metathesis testing for substrates $\mathrm{N}$-(4-phenylbenzylidene)benzylamine (a), N-(4fluorobenzylidene)-4-fluoroaniline (b), and N-benzylidene-tertbutylamine (c).*

\begin{tabular}{c|c|c|cc}
$\begin{array}{c}\text { En } \\
\text { try }\end{array}$ & $\begin{array}{c}\text { Cat } \\
\cdot\end{array}$ & $\begin{array}{c}\text { Time } \\
\text { (h) }\end{array}$ & $\begin{array}{c}\text { Substrate } \\
\text { (Conversion } \\
\text { \%) }\end{array}$ & $\begin{array}{c}\text { Substrate } \\
\text { (Conversion } \\
\text { \%) }\end{array}$ \\
\hline 1 & $\mathbf{2}$ & 1 & $\mathrm{a} \mathrm{(54)}$ & $\mathrm{c} \mathrm{(54)}$ \\
2 & - & 1 & $\mathrm{a} \mathrm{(11)}$ & $\mathrm{c} \mathrm{(11)}$ \\
3 & $\mathbf{1}$ & 1 & $\mathrm{a}(11)$ & $\mathrm{c}(15)$ \\
4 & $\mathbf{2}$ & 6 & $\mathrm{a} \mathrm{(50)}$ & $\mathrm{b}(55)$ \\
5 & - & 6 & $\mathrm{a}(25)$ & $\mathrm{b}(20)$ \\
6 & $\mathbf{2}$ & 4 & $\mathrm{a} \mathrm{(36)}$ & $\mathrm{b} \mathrm{(30)}$ \\
\hline
\end{tabular}

${ }^{*}$ Catalyst $2(0.0031 \mathrm{mmol})$, in toluene $(400 \mu \mathrm{L})$, at $80{ }^{\circ} \mathrm{C}$, both imine substrates $(0.0783 \mathrm{mmol})$. Reaction solution diluted to give a volume of $1 \mathrm{~mL}$; conversion determined by GC-FID.

Products consistent with imine metathesis were identified by GC-MS analyses, as expected, in all the catalytic reaction experiments. In the presence of catalyst $\mathbf{2}$, substrates (a) and (c) reached maximum conversion in just $1 \mathrm{~h}$ (Entry 1, Table 2), resulting in two new products, a" (1-([1,1'-biphenyl]-4-yl)-N-(tertbutyl)methanimine) and $\mathbf{c}^{\prime}$ (N,1-diphenylmethanimine). Control runs (Entry 2, Table 2, and Entry 2, Table S2) with only the substrates or with only $\mathrm{SiO}_{2-700}$ present in the reaction showed reduced reaction rates (giving about $10 \%$ conversion). Furthermore, a run using $\mathbf{1}$ as the catalyst (Entry 3, Table 2) showed a conversion as low as those observed in the other control runs. Taken together, these results indicate that $\mathbf{2}$ is active for imine metathesis, and that the presence of the hafnium imido group is correlated with this performance.

Similar experiments were done with substrates (a) and (b) instead of (a) and (c), and somewhat lower reaction rates were observed, with equilibrium attained in about $6 \mathrm{~h}$ (Entry 3, Table 1), leading to two new products, a' (1-([1,1'-biphenyl]-4-yl)-N-(3fluorophenyl)methanimine) and b' (1-(4-fluorophenyl)-Nphenylmethanimine). These results show that the activities of our catalysts are high in comparison with those reported for this type of catalysis; for example, with a Mo-containing catalyst, ${ }^{12}$ the reaction time was in the range of $6-50 \mathrm{~h}$ for attainment of equilibrium, and for a Zr-containing catalyst, ${ }^{11}$ the time was $12 \mathrm{~h}$.
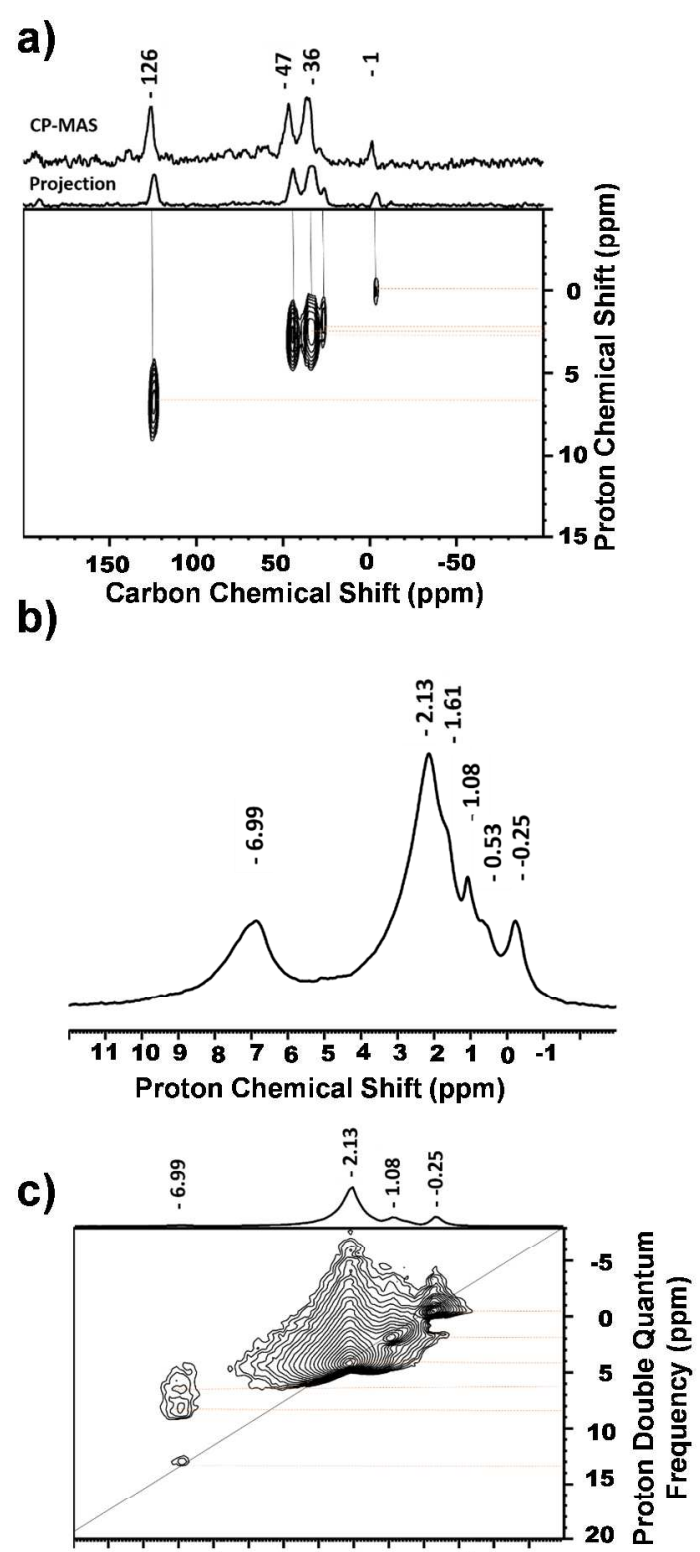

d)
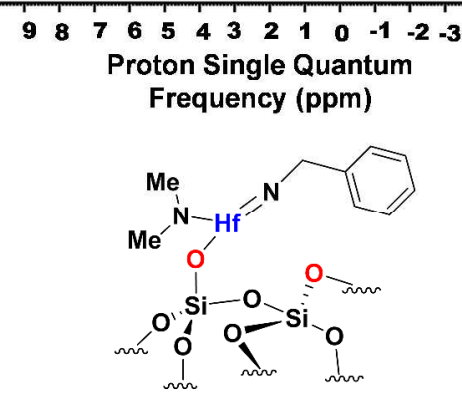

(3)

Figure 6. a) $1 \mathrm{D}{ }^{13} \mathrm{C}$ CP MAS (top) and $2 \mathrm{D}{ }^{1} \mathrm{H}-{ }^{13} \mathrm{C}$ HETCOR (bottom); NMR spectra of $\left[(\equiv \mathrm{Si}-\mathrm{O}-) \mathrm{Hf}\left(=\mathrm{NCH}_{2} \mathrm{Ar}\right)\left(\eta^{1}-\mathrm{NMe}_{2}\right)\right]$ (3); b) $1 \mathrm{D}{ }^{1} \mathrm{H}$ NMR spectrum c) ${ }^{1} \mathrm{H}-{ }^{1} \mathrm{H} \mathrm{DQ}$; d) proposed structure of surface hafnium complex in 3.

The role of the $([M]=N R)$ intermediate in the mechanism was further investigated by derivatizing $\mathbf{2}$ with one of the substrates to generate another fragment. Thus, $\mathbf{2}$ was treated in a batch reactor with $\mathrm{N}$-(4-phenylbenzylidene)benzylamine (a) (detailed in SI) to 
yield 3, which was examined by IR and SS NMR spectroscopies and elemental analysis) (Figures 6, S3, and S4). Comparisons of the IR spectra of $\mathbf{2}$ and $\mathbf{3}$ show the appearance of several bands in the spectrum as 3 formed, in agreement with the presence of aromatic $v(\mathrm{CH})\left(\right.$ at $\left.3050 \mathrm{~cm}^{-1}\right)$ and $\delta(\mathrm{C}=\mathrm{C})\left(\right.$ at $\left.1650-1609 \mathrm{~cm}^{-1}\right)$. Further, elemental analysis showed an increase in the $\mathrm{C} / \mathrm{Hf}$ ratio to 11.3 , consistent with the exchange of a methyl group by a benzyl group (theory: $9 \mathrm{C}$ per Hf atom). The SS NMR spectra of 3 clearly show the presence of aromatic $\delta \mathrm{CH}\left(6.9 \mathrm{ppm}\right.$ in ${ }^{1} \mathrm{H}$ and $126 \mathrm{ppm}$ in $\left.{ }^{13} \mathrm{C}\right)$. We thus propose the structure of $[(\equiv \mathrm{Si}-\mathrm{O}-$ ) $\left.\mathrm{Hf}\left(=\mathrm{NCH}_{2} \mathrm{Ar}\right)\left(\eta^{1}-\mathrm{NMe}_{2}\right)\right]$ (Figures 6 , and $\left.\mathrm{S} 4\right)$ for 3. The data clearly show that the imido ligand undergoes a $2+2$ exchange with the imine substrates. They also confirm the reactivity of the surface fragment $([\mathrm{M}]=\mathrm{NR})$ toward imine substrates and its role in imine metathesis.

Density functional theory (DFT) based calculations were performed to further support the mechanism shown in (Figure 5) using the model species A, shown in (Figure 7). Coordination of the model $\mathrm{Me}-\mathrm{CH}=\mathrm{N}-\mathrm{Me}$ imine to $\mathrm{A}$ is exergonic by 27.7 $\mathrm{kcal} / \mathrm{mol}$ and leads to species $\mathrm{B}$, having a single coordinated imine. Coordination of a second imine, leading to $\mathrm{D}$, is exergonic by $11.4 \mathrm{kcal} / \mathrm{mol}$ only. Based on these considerations, we assumed $\mathrm{B}$ as reference structure at $0 \mathrm{kcal} / \mathrm{mol}$, considering coordination of the second imine as the starting step along the metathesis event. Coordination of both imines occurs via the lone pair on the $\mathrm{N}$ atom, rather than using the $\mathrm{C}=\mathrm{N}$ double bond (Figure 7). The metathesis event from $\mathrm{D}$, via transition state $\mathrm{D}-\mathrm{E}$, requires a reorientation of the imine, to assume a geometry consistent with the classic transition state geometry considered for olefin metathesis (Figure 7), and occurs with the low energy barrier of 10.9 $\mathrm{kcal} / \mathrm{mol}$. Evolution of transition state D-E towards the products converges into the metallacycle E, $19.1 \mathrm{kcal} / \mathrm{mol}$ lower in energy compared to D. For the sake of consistency, we also examined metathesis from the single imine coordinated intermediate $\mathrm{B}$. The reaction occurs via transition state $\mathrm{B}-\mathrm{C}$, with an energy barrier of $5.0 \mathrm{kcal} / \mathrm{mol}$, and would converge into the metallacycle $\mathrm{C}, 15.0$ $\mathrm{kcal} / \mathrm{mol}$ lower in energy than B. This indicates that coordination of the second imine has moderate impact on the energy barrier for the metathesis event. The most stable structure along the reaction profile is the metallacycle, indicating that liberation of the product might reveal as the rate limiting step along the reaction profile.

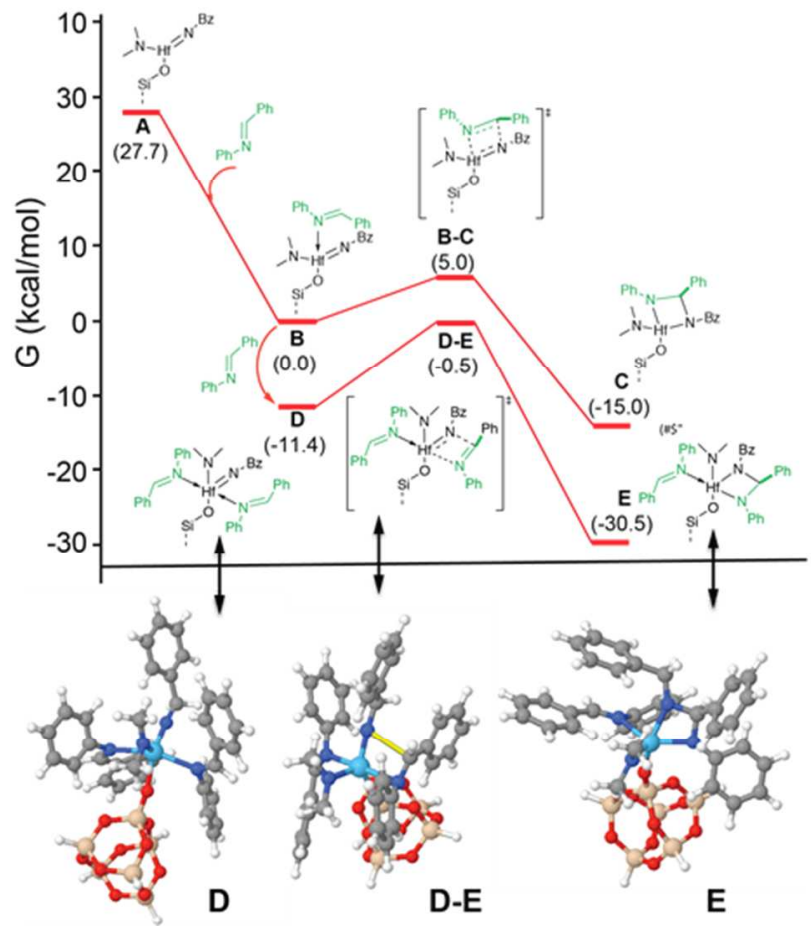

Figure 7. DFT energy profile for imine metathesis, with a 3D sketch of intermediates D and E, and transition state D-E. All calculations at the M06/SDD/TZVP//PBE1PBE/SDD/SVP level of theory. The emerging $\mathrm{C}-\mathrm{N}$ bond in transition state $\mathrm{D}-\mathrm{E}$ is colored in yellow.

\section{CONCLUSIONS}

We report the preparation of new silica-supported hafnium complexes 1, 2, and 3 complemented by their characterization by SS NMR and IR spectroscopies and elemental analysis. Further characterizations were carried out with EXAFS spectroscopy, giving structural information about $\mathbf{1}$, and ${ }^{15} \mathrm{~N}$ MAS DNP SENS data were obtained characterizing $\mathbf{1}$ and $\mathbf{2}$. The data demonstrate the presence of surface fragments $(\mathrm{MNC})$ in $\mathbf{1},\left[(\equiv \mathrm{Si}-\mathrm{O}-) \mathrm{Hf}\left(\eta^{2} \pi-\right.\right.$ $\left.\left.\mathrm{MeNCH}_{2}\right)\left(\eta^{1}-\mathrm{NMe}_{2}\right)\left(\eta^{1}-\mathrm{HNMe}_{2}\right)\right]$, and $([\mathrm{M}]=\mathrm{N})$ in $\mathbf{2}$ and $\mathbf{3}$, $\left[(\equiv \mathrm{Si}-\mathrm{O}-) \mathrm{Hf}(=\mathrm{NMe})\left(\eta^{1}-\mathrm{NMe}_{2}\right)\right]$ and $\left[(\equiv \mathrm{Si}-\mathrm{O}-) \mathrm{Hf}\left(=\mathrm{NCH}_{2} \mathrm{Ar}\right)(\eta\right.$ $\left.\left.{ }^{1}-\mathrm{NMe}_{2}\right)\right]$, respectively. The pivotal role of $([\mathrm{M}]=\mathrm{NR})$ in metathesis of imine was demonstrated in catalyst testing with two pairs of substrates. The proposed reaction mechanism is also supported by DFT calculations.

\section{ASSOCIATED CONTENT}

\section{Supporting Information}

The Supporting Information is available free of charge on the ACS Publications website at DOI:

Elemental analysis, NMR Characterization, substrate analysis, and blank tests; Tables S1-S2; Figures S1-S6 (PDF).

EXAF data analysis details; Tables S3-S4; Figures S7 (PDF).

\section{AUTHOR INFORMATION}

\section{Corresponding Author}

*Email: luigi.cavallo@kaust.edu.sa ， bcgates@ucdavis.edu , jeremie.pelletier@kaust.edu.sa , $\quad \frac{\text { and jeanma- }}{}$ rie.basset@kaust.edu.sa 


\section{Notes}

The authors declare no competing financial interests.

\section{ACKNOWLEDGMENTS}

The research was supported by the King Abdullah University of Science and Technology (KAUST). The authors acknowledge core lab at KAUST for their assistance. The work at the University of California was supported by the U.S. Department of Energy, Basic Energy Sciences, Grant Number DE-FG02-04ER15513. We acknowledge the European Synchrotron Radiation Facility for provision of synchrotron radiation facilities and thank Antonio Aguilar for assistance in using beamline BM30 B.

\section{REFERENCES}

(1) Pelletier, J. r. m. D.; Basset, J.-M., Catalysis by Design: WellDefined Single-Site Heterogeneous Catalysts, Acc. Chem. Res. 2016, 49, 664-677.

(2) Basset, J.-M.; Psaro, R.; Roberto, D.; Ugo, R., Modern surface organometallic chemistry. John Wiley \& Sons: 2009;

(3) Hamzaoui, B.; Pelletier, J. D.; Abou-Hamad, E.; Basset, J.-M., Well-defined silica-supported zirconium-imido complexes mediated heterogeneous imine metathesis, Chem. Commun. 2016, 52, 4617-4620.

(4) Hamzaoui, B.; Pelletier, J. D. A.; El Eter, M.; Chen, Y.; AbouHamad, E.; Basset, J.-M., Isolation and Characterization of WellDefined Silica-Supported Azametallacyclopentane: A Key Intermediate in Catalytic Hydroaminoalkylation Reactions, Adv. Synth. Catal. 2015, 357, 3148-3154.

(5) Blanc, F.; Copéret, C.; Thivolle-Cazat, J.; Basset, J.-M., Alkane Metathesis Catalyzed by a Well-Defined Silica-Supported Mo Imido Alkylidene Complex: [( $=\mathrm{SiO}) \mathrm{Mo}(=\mathrm{NAr})(=\mathrm{CHtBu})(\mathrm{CH} 2 \mathrm{tBu})]$, Angew. Chem., Int. Ed. 2006, 45, 6201-6203.

(6) Schrock, R. R.; Hoveyda, A. H., Molybdenum and Tungsten Imido Alkylidene Complexes as Efficient Olefin-Metathesis Catalysts, Angewandte Chemie International Edition 2003, 42, 4592-4633.

(7) Ingold, C. K.; Piggott, H. A., CCLXXXVII.-The mobility of symmetrical triad systems. Part I. The conditions relating to systems terminated by phenyl groups, Journal of the Chemical Society, Transactions 1922, 121, 2381-2389.

(8) Tóth, G.; Pintér, I.; Messmer, A., Mechanism of the exchmge reaction of aromatic scriff bases, Tetrahedron Lett. 1974, 15, 735738.

(9) Meyer, K. E.; Walsh, P. J.; Bergman, R. G., Zirconium-Mediated Imine Metathesis. Synthesis of 2, 4-Diaza-1-zirconiacyclobutanes and the Mechanism of Their Reactions with Imines and Alkynes, J. Am. Chem. Soc. 1994, 116, 2669-2670.

(10) Ciaccia, M.; Di Stefano, S., Mechanisms of imine exchange reactions in organic solvents, Org. Biomol. Chem. 2015, 13, 646654.

(11) Hamzaoui, B.; Pelletier, J. D. A.; Abou-Hamad, E.; Basset, J.M., Well-defined silica-supported zirconium-imido complexes mediated heterogeneous imine metathesis, Chem. Commun. 2016, 52, 4617-4620.

(12) Barman, S.; Merle, N.; Minenkov, Y.; De Mallmann, A.; Samantaray, M. K.; Le Quéméner, F.; Szeto, K. C.; Abou-Hamad, E.; Cavallo, L.; Taoufik, M.; Basset, J.-M., Well-Defined Silica Grafted Molybdenum Bis(imido) Catalysts for Imine Metathesis Reactions, Organometallics 2017, 36, 1550-1556.

(13) Copéret, C.; Chabanas, M.; Petroff Saint - Arroman, R.; Basset, J. M., Homogeneous and heterogeneous catalysis: bridging the gap through surface organometallic chemistry, Angew. Chem., Int. Ed. 2003, 42, 156-181.

(14) Hamzaoui, B.; Eter, M. E.; Abou-hamad, E.; Chen, Y.; Pelletier, J. D. A.; Basset, J.-M., Well-Defined Single-Site Monohydride Silica-Supported Zirconium from Azazirconacyclopropane, Chem. Eur. J 2015, 21, 4294-4299. (15) El Eter, M.; Hamzaoui, B.; Abou-Hamad, E.; Pelletier, J. D.; Basset, J.-M., Well-defined azazirconacyclopropane complexes supported on silica structurally determined by 2D NMR comparative elucidation, Chem. Commun. 2013, 49, 4616-4618. (16) Jentoft, R.; Deutsch, S.; Gates, B., Low - cost, heated, and/or cooled flow - through cell for transmission $\mathrm{x}$ - ray absorption spectroscopy, Rev. Sci. Instrum. 1996, 67, 2111-2112.

(17) Bauer, M.; Müller, S.; Kickelbick, G.; Bertagnolli, H., The structures of the precursor $\mathrm{Hf}(\mathrm{O} \cap \mathrm{Bu}) 4$ and its modification in solution: EXAFS-investigation in combination with XANES-and IRspectroscopy, New Journal of Chemistry 2007, 31, 1950-1959. (18) Froese, R. D.; Jazdzewski, B. A.; Klosin, J.; Kuhlman, R. L.; Theriault, C. N.; Welsh, D. M.; Abboud, K. A., Imino-amido Hf and Zr complexes: synthesis, isomerization, and olefin polymerization, Organometallics 2010, 30, 251-262. (19) Frank, D.; Baumgartner, J.; Marschner, C., First successful reaction of a silyl anion with hafnium tetrachloride, Chem. Commun. 2002, 1190-1191.

(20) Scott, M. J.; Lippard, S. J., Isocyanide Insertion Reactions with Organometallic Group 4 Tropocoronand Complexes: Formation of $\eta$ 2-Iminoacyl, Enediamido, $\eta 2$-Imine, and $\mu$ Imido Products, Organometallics 1997, 16, 5857-5868.

\section{TOC}




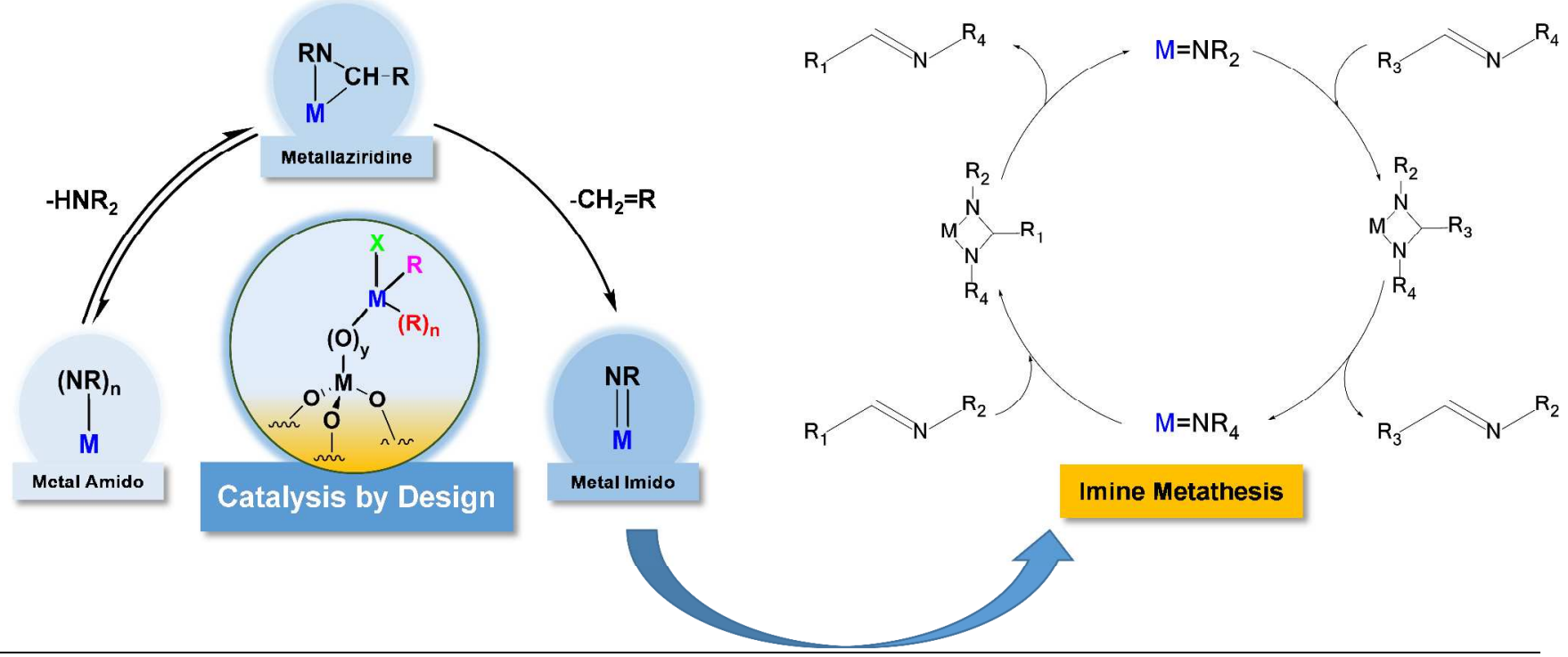

